David Bracco Francesco Donatelli

\title{
Volatile agents for ICU sedation?
}

Received: 21 February 2011

Accepted: 22 February 2011

Published online: 29 March 2011

(C) Copyright jointly held by Springer and ESICM 2011

This editorial refers to the article available at: doi:10.1007/s00134-011-2187-3.

D. Bracco $(\bowtie) \cdot$ F. Donatelli

Anesthesia and Intensive Care Department,

McGill University, Montreal, Canada

e-mail: david.bracco@mcgill.ca

Tel.: +1-514-9341934

Fax: +1-514-9348249

Sedation is a standard part of critical care and was unchallenged from 1960 to 2000. Classical sedation approaches are associated with significant post-traumatic stress traits [1]. Because of poor pharmacokinetics/pharmacodynamics and planning problems, patients in the intensive care unit (ICU) spend one-third of their duration of stay being ventilated after the resolution of the problem mandating intubation $[2,3]$. The aim of sedation in the ICU is to make the patient calm and tolerant to the critical care therapies, in particular mechanical ventilation. Recently several approaches have proven beneficial for patient care and the healthcare system: prospective trials have shown that daily interruptions of sedation are associated with a decrease in length of ventilation and decrease in ICU stay [4]. If a spontaneous breathing trial is used in addition to daily sedation interruption, the 1-year survival is improved [5] without an increase in psychological consequences [6]. Recent data suggest that no sedation at all may be better [7]. This move has been made possible by the improvement in ventilator algorithms, which are increasingly flexible in dealing with variable patient efforts. Over the last 10 years, the pendulum has moved toward a decrease in sedation with proactive strategies [8]. In this frame, the quest for the ideal sedation agent is continuing. The ideal sedative agent should be fast acting, have a rapid onset, not be organ dependent in terms of degradation, not have metabolically active or toxic by-products, have little cardiovascular effects, and be cheap. Over the last 30 years, midazolam, propofol [9], and dexmedetomidine $[10,11]$ have been rolled out with the promise of being better than the previous generation of drugs.

Sedation management in the ICU is a complex process involving sedation level assessment, medication administration, and an overall strategy. These three components are essential for correct ICU sedation. No one will give norepinephrine in the ICU without measuring blood pressure and having a strategy and objectives for vasopressor use, i.e., norepinephrine up to $20 \mu \mathrm{g} / \mathrm{min}$ for a mean arterial pressure (MAP) of $65 \mathrm{mmHg}$. Why are we tolerating this "art" of sedation and analgesia in the ICU? There is confusion in the literature between sedation/ hypnosis, analgesia, delirium management, and relaxation. This is shown by a recent meta-analysis regarding dexmedetomidine [12] pooling studies on dexmedetomidine used with sedation end points, morphine-sparing end points, and delirium end points. A hypnotic is a hypnotic, an analgesic is an analgesic, an antipsychotic is a drug used to treat delirium episodes [13], and a neuromuscular blocker is a relaxant medication. Although these classes of drugs have synergistic effects they cannot be used interchangeably.

Volatile anesthesia agents have been in use for 50 years in anesthesia but only marginally in the ICU $[14,15]$. The first volatile agents were hepatotoxic and induced significant arrhythmias, which make then unsuitable for longterm ICU sedation. Sevoflurane is a very versatile inhalational anesthesia agent with interesting neuro- [16] and cardioprotective [17] properties. Its kinetic and marginal organ degradation make it interesting in the ICU setting. Its applicability depends on the ICU staff and their 
Table 1

\begin{tabular}{|c|c|c|c|}
\hline & Propofol & Dexmedetomidine & Sevoflurane \\
\hline \multirow[t]{4}{*}{ Advantages } & \multirow{4}{*}{$\begin{array}{l}\text { Rapid onset, can be used for induction } \\
\text { and as bolus for rapid control } \\
\text { Does not need specialized equipment }\end{array}$} & No respiratory depression & No organ-dependent degradation \\
\hline & & Co-analgesic properties & Easy titration up and down \\
\hline & & Less delirium & $\begin{array}{l}\text { Titration based on measured } \\
\text { concentrations }\end{array}$ \\
\hline & & & Shortest awakening/extubation times \\
\hline \multirow[t]{3}{*}{ Disadvantages } & \multirow{3}{*}{$\begin{array}{l}\text { Significant administration of } \\
\text { (nutritionally unhealthy) lipids } \\
\text { Propofol infusion syndrome } \\
\text { Context-sensitive pharmacokinetics }\end{array}$} & Insufficient potency for deep sedation & Requires investment and training \\
\hline & & Bradycardia, hypotension & Malignant hyperthermia \\
\hline & & Rebound hypertension on withdrawal & $\begin{array}{l}\text { Cannot be used as a "bolus" for } \\
\text { induction routinely }\end{array}$ \\
\hline $\begin{array}{l}\text { Approx. cost } \\
\text { per } 24 \mathrm{~h}\end{array}$ & $€ 44$ & $€ 189$ & Anaconda, $€ 65$; vaporizer, $€ 47$ \\
\hline
\end{tabular}

Costs based on $70 \mathrm{~kg} 80 \mu \mathrm{g} / \mathrm{kg} / \mathrm{min}$ for propofol, $0.5 \mu \mathrm{g} / \mathrm{kg} / \mathrm{h}$ for dexedetomidine, and $4 \mathrm{ml} / \mathrm{h}$ sevoflurane for an Anaconda (anesthetic conserving device) and $1 \%$ at $1 \mathrm{~L} / \mathrm{min}$ fresh gas flow for vaporizer. Costs translated from Canadian prices

background: Anesthetists handle volatile agents daily in the operating room (OR), are familiar with the concepts of end tidal concentration and minimum alveolar concentration, and are prepared in the unlikely event of a malignant hyperthermia reaction. The paper by Capdevila et al. [18] in this issue of Intensive Care Medicine is welcome and shows the feasibility of sevoflurane anesthesia in uncomplicated ICU patients. The authors show that awakening and extubation times are much shorter with sevoflurane compared with those using midazolam or propofol. These awakening and extubation times almost compete with the sub-10-min anesthesia awakening times [19]. These encouraging preliminary data should be analyzed with caution because out of 438 intubated sedated patients admitted in their unit only $60(14 \%)$ were randomized. ICU is traditionally associated with protracted recovery and very slow functional rehabilitation [20]. Sedation weaning is associated with a long time to extubation, a long time to get out of bed, and a long time to regain functional autonomy. Although the study by Capdevila et al. was not designed or powered to determine a difference in ICU length of stay or mortality, the predictability and quality of awakening makes the use of sevoflurane very interesting.

Adoption of volatile agent sedation in the ICU should be done with caution: There are very little data on it is administration over more than $24 \mathrm{~h}$ in various patient populations. We think that fluoride generation from sevoflurane is minimal and below toxic ranges, but longer administration in patients with impaired renal function may prove otherwise. Sevoflurane implementation in the ICU will require engineering upgrade of a significant part of the ICU for gas-scavenging infrastructure, and technical investments such as the filters, sevoflurane delivery pumps, and gas analyzer. This implementation will also require an important educational intervention directed at the physicians, nurses, and respiratory therapists. Knowledge about agents and malignant hyperthermia has to be maintained round the clock across all shifts and staff rotations.

ICU sedation has to move from the amorphous, catabolic, cachectic, amyotrophic ICU patient [21] to the proactive, tolerant, and participative patient $[22,23]$. If a patient needs a procedure, e.g., tracheostomy, lines, dressing change, the patient needs to be deeply anesthetized. However, outside these periods he needs to be awake [24]. At all times perfect analgesia should be provided with potent opioids and a locoregional analgesia technique when feasible. In this context, sevoflurane certainly has a place in ICU sedation (Table 1); sevoflurane will not replace propofol, dexmedetomidine, or other hypnotic agents but it may be a very promising complement to allow predictable and fast awakening.

\section{References}

1. Samuelson KA, Lundberg D, Fridlund B (2007) Stressful memories and psychological distress in adult mechanically ventilated intensive care patients-a 2-month follow-up study. Acta Anaesthesiol Scand 51:671-678
2. Esteban A, Anzueto A, Alia I, Gordo F, Apezteguia C, Palizas F, Cide D, Goldwaser R, Soto L, Bugedo G, Rodrigo C, Pimentel J, Raimondi G, Tobin MJ (2000) How is mechanical ventilation employed in the intensive care unit? An international utilization review. Am J Respir Crit Care Med $161: 1450-1458$
3. Esteban A, Anzueto A, Frutos F, Alia I, Brochard L, Stewart TE, Benito S, Epstein SK, Apezteguia C, Nightingale P, Arroliga AC, Tobin MJ (2002) Characteristics and outcomes in adult patients receiving mechanical ventilation: a 28 -day international study. JAMA 287:345-355 
4. Kress JP, Pohlman AS, O'Connor MF, Hall JB (2000) Daily interruption of sedative infusions in critically ill patients undergoing mechanical ventilation. N Engl J Med 342:1471-1477

5. Girard TD, Kress JP, Fuchs BD, Thomason JW, Schweickert WD, Pun BT, Taichman DB, Dunn JG, Pohlman AS, Kinniry PA, Jackson JC, Canonico AE, Light RW, Shintani AK, Thompson JL, Gordon SM, Hall JB, Dittus RS, Bernard GR, Ely EW (2008) Efficacy and safety of a paired sedation and ventilator weaning protocol for mechanically ventilated patients in intensive care (awakening and breathing controlled trial): a randomised controlled trial. Lancet 371:126-134

6. Jackson JC, Girard TD, Gordon SM, Thompson JL, Shintani AK, Thomason JW, Pun BT, Canonico AE, Dunn JG, Bernard GR, Dittus RS, Ely EW (2010) Long-term cognitive and psychological outcomes in the awakening and breathing controlled trial. Am J Respir Crit Care Med 182:183-191

7. Strom T, Martinussen T, Toft P (2010) A protocol of no sedation for critically ill patients receiving mechanical ventilation: a randomised trial. Lancet 375:475-480

8. Schweickert WD, Kress JP (2008) Strategies to optimize analgesia and sedation. Crit Care 12(Suppl 3):S6

9. Carson SS, Kress JP, Rodgers JE, Vinayak A, Campbell-Bright S, Levitt J, Bourdet S, Ivanova A, Henderson AG, Pohlman A, Chang L, Rich PB, Hall J (2006) A randomized trial of intermittent lorazepam versus propofol with daily interruption in mechanically ventilated patients. Crit Care Med 34:1326-1332
10. Pandharipande PP, Pun BT, Herr DL, Maze M, Girard TD, Miller RR, Shintani AK, Thompson JL, Jackson JC, Deppen SA, Stiles RA, Dittus RS, Bernard GR, Ely EW (2007) Effect of sedation with dexmedetomidine vs lorazepam on acute brain dysfunction in mechanically ventilated patients: the MENDS randomized controlled trial. JAMA 298:2644-2653

11. Riker RR, Shehabi Y, Bokesch PM, Ceraso D, Wisemandle W, Koura F, Whitten P, Margolis BD, Byrne DW, Ely EW, Rocha MG (2009) Dexmedetomidine versus midazolam for sedation of critically ill patients: a randomized trial. JAMA 301:489-499

12. Tan JA, Ho KM (2010) Use of dexmedetomidine as a sedative and analgesic agent in critically ill adult patients: a meta-analysis. Intensive Care Med 36:926-939

13. Devlin JW, Roberts RJ, Fong JJ, Skrobik Y, Riker RR, Hill NS, Robbins T, Garpestad E (2010) Efficacy and safety of quetiapine in critically ill patients with delirium: a prospective, multicenter, randomized, double-blind, placebo-controlled pilot study. Crit Care Med 38:419-427

14. Sackey PV, Martling CR, Carlsward C, Sundin O, Radell PJ (2008) Short- and long-term follow-up of intensive care unit patients after sedation with isoflurane and midazolam-a pilot study. Crit Care Med 36:801-806

15. Sackey PV, Martling CR, Granath F, Radell PJ (2004) Prolonged isoflurane sedation of intensive care unit patients with the anesthetic conserving device. Crit Care Med 32:2241-2246

16. Matchett GA, Allard MW, Martin RD, Zhang JH (2009) Neuroprotective effect of volatile anesthetic agents: molecular mechanisms. Neurol Res 31:128-134

17. Pratt PF Jr, Wang C, Weihrauch D, Bienengraeber MW, Kersten JR, Pagel PS, Warltier DC (2006) Cardioprotection by volatile anesthetics: new applications for old drugs? Curr Opin Anaesthesiol 19:397-403
18. Mesnil M, Capdevila X, Bringuier S, Trine P-O, Falquet Y, Charbit J, Roustan J-P, Chanques G, Jaber S (2011) Long-term sedation in intensive care unit: a randomized comparison between inhaled sevoflurane and intravenous propofol or midazolam. Intensive Care Med. doi: 10.1007/00134-011-2187-3

19. White PF, Tang J, Wender RH, Yumul $\mathrm{R}$, Stokes OJ, Sloninsky A, Naruse R, Kariger R, Norel E, Mandel S, Webb T, Zaentz A (2009) Desflurane versus sevoflurane for maintenance of outpatient anesthesia: the effect on early versus late recovery and perioperative coughing. Anesth Analg 109:387-393

20. van der Schaaf M, Beelen A, Dongelmans DA, Vroom MB, Nollet F (2009) Poor functional recovery after a critical illness: a longitudinal study. J Rehabil Med 41:1041-1048

21. Griffiths RD, Hall JB (2010) Intensive care unit-acquired weakness. Crit Care Med 38:779-787

22. Schweickert WD, Pohlman MC, Pohlman AS, Nigos C, Pawlik AJ, Esbrook CL, Spears L, Miller M, Franczyk M, Deprizio D, Schmidt GA, Bowman A, Barr R, McCallister KE, Hall JB, Kress JP (2009) Early physical and occupational therapy in mechanically ventilated, critically ill patients: a randomised controlled trial. Lancet 373:1874-1882

23. Pohlman MC, Schweickert WD, Pohlman AS, Nigos C, Pawlik AJ, Esbrook CL, Spears L, Miller M, Franczyk M, Deprizio D, Schmidt GA Bowman A, Barr R, McCallister K, Hall JB, Kress JP (2010) Feasibility of physical and occupational therapy beginning from initiation of mechanical ventilation. Crit Care Med 38:2089-2094

24. Hall JB (2010) Creating the animated intensive care unit. Crit Care Med 38:S668-S675 